\title{
Will Aesthetics English Comic Books Make Junior High School Students Fall in Love with English Reading?
}

\author{
Chou Mei-Ju ${ }^{1, *}$, Hsu Yung-Hung ${ }^{2}$, Chen Ching-Chi \\ ${ }^{1}$ Early Childhood Education \& Center for Teacher Education, National Pingtung University, Taiwan \\ ${ }^{2}$ Department of English, National Kaohsiung Normal University, Taiwan
}

Copyright (C) 2015 by authors, all rights reserved. Authors agree that this article remains permanently open access under the terms of the Creative Commons Attribution License 4.0 International License

\begin{abstract}
The present study aims to investigate the effects of Aesthetics English comic books on EFL junior high school students' vocabulary acquisition, reading comprehension, and English learning motivation. The participants in this study were 28 eighth graders from one class in a public junior high school in Pingtung in Taiwan. After ten weeks instruction of comic books, students take two tests and a post-study questionnaire. Based upon the quantitative and qualitative data analysis, the findings of the present study are summarized as follows. First of all, all of them significantly improved their amount of vocabulary after the comic-book reading program (CBRP). As for the contrast between the $\mathrm{HG}$ and the $\mathrm{LG}$, the former outperformed the latter and the result reached a significant difference. Second, based on their scores from the reading pretest to the post-test, all of them enhanced their reading comprehension ability posterior to the CBRP and the result reached a significant difference. Third, according to the analysis of the questionnaires, up to $86 \%$ of them think it is a good way to apply English comic books to English instruction; about 79\% of them agreed that they like to read English comic books better than before. On the basis of the study findings, the comic book-reading program can indeed enhance students' vocabulary acquisition, reading comprehension as well as their learning motivation.
\end{abstract}

Keywords Aesthetics, English Comic Books, Vocabulary Acquisition, Reading Comprehension, Learning Motivation

\section{Introduction}

As early as 1989, Schouten-van Parreren pointed out the problem of vocabulary learning and instruction:

One of the main difficulties facing pupils in foreign language learning, lies in the huge number of words they have to acquire. Although this fact is widely acknowledged, the methods used in school practice are, on the whole, not very effective and even demotivating (p. 75).

Ironically, Parreren's description still matches the current English language instruction in most of the classrooms in Taiwan. In the most cases, English instruction is carried out under the Grammar-Translation Method (GTM), in which sentence structures and grammar translation are centered around (Practor \& Celce-Murcia, 1979). [1] Students are forced to memorize the isolated words in the list. For teachers, it is a convenient and fast teaching method; however, the results are apparently ineffective.

What's worse, poor vocabulary learning directly leads to bad performances in other language aspects, especially in reading comprehension. Numerous researches have shown that vocabulary knowledge and the development of reading comprehension positively correlates with each other (Grabe, 2009; Perfetti, Landi, \& Oakhill, 2005;Zhang, 2012).[2][3][4]

Several decades ago, comic-book reading was viewed as an interference with school learning and even a connection to committing crimes. Dr. Wertham, in his famous book, Seduction of the Innocent (1954), severely asserted that "comic books are death on reading" (121). He went on criticizing comics' negative influence on children's reading abilities and those who read comics were "book worms without books". Fortunately, later more and more researchers uncovered its veil of misconception by presenting concrete research evidence (Krashen, 2004).[5] In addition, more recently, comics with its unique charm has not only become popular reading materials but its application in literacy education has also mushroomed like bamboo shoots after a spring rain (Frey \& Fisher, 2014; Jacobs, 2007; Nixon, 2012).[6][7][8]

Based upon the notion above, an idea occurred to the researcher, "Is it an effective way to facilitate vocabulary acquisition and reading comprehension by reading Aesthetics English comics?" Although it has been widely recognized that reading plays a crucial part in linguistic development, English comic-book reading was once a controversial issue in English Instruction. If comic reading are discussed as arts, they are often considered as a part of 
the literary enterprise or as a static variety of film (Seranted, 2010; Bongco, 2014; Phghe, 2013).[9][10][11]Focusing on the educational benefits of comic books, the study aims to realize whether the aesthetics comic books of unique of art form could cultivate students' vocabulary acquisition, reading comprehension, and English learning motivation.

Numerous related studies, most of them are centered around comics' application in education (Brown, 2006; Choo, 2010; Chute, 2008; Davis, 2012; Flaig, 2013; Gardner, 2014) [12][13][14][15][16][17]: their research topics are mostly focused on reading comprehension; partly on writing application and on vocabulary acquisition. However, none of them is from the aesthetics perspective to investigate the students' reading. Therefore, this experimental research was set to investigate the comics' effects on vocabulary acquisition and reading comprehension from the aesthetics comic perspective. Hence, it anticipated to provide pedagogical suggestions for English instructors interested in the topic of aesthetic reading.

Specifically, the present study was conducted for the following purposes:

- To investigate the effects of the English aesthetics comic-book reading on the subjects' vocabulary acquisition.

- To investigate the effects of the English aesthetics comic-book reading on the subjects' reading comprehension.

- To explore the effects of the English aesthetics comic-book reading on high-and low- proficiency subjects' vocabulary acquisition.

- To explore the effects of the English aesthetics comic-book reading on high-and low- proficiency subjects' reading comprehension.

- To observe and compare the subjects' attitudes and responses before and after the treatment of the English aesthetics comic-book reading in the process of language learning.

On the basis of the study purposes, the following research questions are addressed:

- Does the English aesthetics comic-book reading improve junior high school students' vocabulary acquisition?

- Does the English aesthetics comic-book reading enhance junior high school students' reading comprehension?

- Do high-proficiency learners acquire more vocabulary than low-proficiency ones from the English aesthetics comic-book reading program?

- Do high-proficiency learners make more progress in reading comprehension than low-proficiency ones from the English aesthetics comic-book reading program?

- What are junior high school students' motivation and attitudes towards English aesthetic comic learning before and after the treatment?

\section{Related Literature}

\subsection{Aesthetics Comics Application in Learning Instruction}

More recently, comics with its special charm, especially from the aesthetic literacy perspective (Bongco, 2014; Gardner, 2014; Lewis, 2010; Pughe, 2013; Stockwell, 2012) [10][17][18][11][19] have become the research topic of popular reading materials; furthermore, some researches on exploring its application in literacy education are presented (Frey \& Fisher, 2014; Jacobs, 2007).[6][7] For the application of popular media in the literacy activities has grown more prevalent, and these media can catch students' attention in their own way, they can serve as a frame of reference and familiar territory for thinking about narrative (Gardner, 2014) [17]. Comics, an emerging field for literacy researchers, are a branch of the media (Morrison, Bryan, \& Chilcoat, 2002). [20] Krashen (2004: 109-110) [5] further claimed that the case for comics is a good one:

- The texts of comics are linguistically appropriate, and the aesthetics pictures can help make the texts comprehensible.

- Research shows that comics have no negative effect on language development and school achievement.

- There is strong evidence from case studies that comics can serve as a conduit to book reading.

What is more, in 2004, state educators in Maryland launched what is believed to be the first statewide program to promote the use of comics in schools (Viadero, 2009)[21]. In short, compared with carefully designed textbooks, comics have a kind of special charm that attracts students' attention: (1) the enhancement of reading comprehension and writing skills: In the past, educators used to worry that reading comics would hinder students' reading abilities because of the simplicity combined with the texts and visual representation. In fact, numerous studies have shown that reading comics are able to cultivate visual literacy skills which facilitate reading comprehension (Carter, 2007; Cleaver, 2008)[22][23] As Krashen (2004)[5] pointed out, the visual narrative that accompanies the text in comic books "can provide clues that shed light on the meaning of an unfamiliar word or grammatical structure" (p. 402). Furthermore, Norton and Vanderheyden (2004)[24] mentioned that students found that the colorful pictures, contextualized vocabulary and interesting content enhanced their interest in reading. In the light of the combination between texts and pictures, second/additional-language learners can comprehend the text's meaning through the invaluable pictorial representation (Bongco, 2014; Davis, 2012).[10][15]

(2) multi-function educational purposes: Viadero's (2009) [21]stated that educators are using the medium for a variety of purposes, including:

- a bridge to full literacy for English-language learners and struggling readers

- a tool for discussing sensitive social issues 
- a subject for lessons on visual literacy

- a vehicle for ethics discussion in classes with gifted students

- a means for nurturing creativity in after-school programs (p. 11)

(3) behavioral remediation: As Michael Bitz, founder of the Comic Book Project at the Columbia University School of Education says, "Suddenly these kids known for behavior problems during typical reading and writing activities were the most engaged during comic book lessons. "They collaborated and started to work together to become part of education, whereas before they were shut out." (4) the enhancement of writing skills: As Frey and Fisher (2004) noted, "These forms of popular culture [graphic novels] provided a visual vocabulary for all sorts of scaffolding, writing techniques, particularly dialogue, tone, and mood" ( $\mathrm{p}$. 24).

\subsection{Empirical Studies of Comics in Language Instruction}

Not so many years ago, reading comics was not allowed at school, most of the teachers were reluctant to use comics as the resource in literacy instruction. In fact, such a phenomenon results from the misconception of comics. Recently more and more empirical or experimental investigation studies have shown that comics do facilitate students' literacy abilities.

Morrison et al.'s (2002)[20] study on the use of student-generated comic books described "how comic-book design can be used to help students develop their writing, comprehension, and research skills in a cross-curricular activity" (p. 759). Morrison et al. embodied the comic-book construction, which provided the guidelines for the following research or implementation of integrating comic books into instruction. For example, Ranker (2007) [25]narrated Morrison et al.'s perspectives: "Because of their capacity to increase interest and motivation, comic books are also an effective way of increasing reading comprehension and teaching comprehension strategies."

Followed by Morrison et al.'s study, numerous researchers exalted the application of the comics in literacy education (Bringelson, 2010; Chun, 2009; Cleaver,2008).[26][27][23] Bringelson (2010) advocated that teachers should integrate comics in the literacy instruction. They thought that comics were not necessarily simplistic; instead, they claimed that " a well-done comic can be like a poem. A poem can be simple, but it has a purity and it is honed down to a form that allows it to acquire depth" (p. 23).

Chun's (2009)[27] study on integrating the graphic novel (Maus) in the aesthetics literacy activities mentioned that graphic novels with substantive content are accessible to even high-intermediate ELL students. He attributed the feasibility to "their scaffolding of textual meanings through their rich visual modes of representation" (p. 146). Cleaver (2008)[23] also narrated that graphic novels are not merely viewed as educational tools but they are also regarded as literature and an art form. What's more, comic books can arouse reluctant readers' interest and challenge the students fluent in more traditional literature

Contrastive to the empirical studies above, Liu (2004) [28]conducted an experiment investigating the effects of comic strips on ESL learners' reading comprehension. His study further helped to resolve theoretical and practical issues in L2 reading by investigating to what extent including comics as visual support for ESL texts increases reading comprehension. Liu (2004) [28]concluded that for low-level students, comic strips with reading text are conducive to comprehending the text. Also, the effect of comic strips on reading comprehension depends largely on the quality of the repetition effect.

In conclusion, numerous literacy researchers have unveiled the effects of comics on literacy instruction, especially on reading comprehension. It is a pity that few literacy researchers investigate the effects of comics on students' vocabulary acquisition. In addition, quite a few researches, scholars and comic artists highly praise invaluable effects of comics. As Wiley Miller, comic artist and author of the Ordinary Basil series, says, "Trying to dissuade kids from reading comics is silly and juvenile-it hurts kids." However, integrating comics into literacy instruction for most teachers is faced with many challenges.

\subsection{Related Learning Theories about Comic Instruction}

Speaking of related learning theories concerning comics instruction, below are the frequently-adopted theories: dual-coding theory, the input hypothesis and the affective filter hypothesis. They are introduced in detail as follows.

\subsubsection{Dual-coding Theory}

Numerous literacy researchers have proved that reading comics can facilitate students' reading comprehension instead of being the hindrance to reading. The enhancement of the reading comprehension results from the cultivation of visual literacy skills (Carter, 2007; Cleaver, 2008).[22][23] In the light of comics' unique characteristic, the combination between words and pictures, the dual coding theory (DCT) can perhaps provide a theoretical background.

Dual-coding theory, a theory of cognition, was hypothesized by Allan Paivio in 1971. According to Paivio, we could expand on learned materials in two ways: verbal associations and visual imagery. In this theory, the linguistic coding system can be called the verbal system, and the nonverbal coding system can be called the imagery system. The theory postulates that both systems are used to represent information. The ability to code information two different ways increases the chance of remembering that item compared to if it is only coded one way. According to Sadoski and Paivio (2001),[29] "the structuring and processing of these mental representations, or encodings, is the basis of all cognition in this theory" (p. 43).

Recently, numerous literacy researchers have used DCT 
as a theoretical framework for studying reading comprehension. They have found that pictures containing substantive information improve reading comprehension and memory. For example, Mayer (2003a)[30] investigated multimedia instructional design based on a cognitive theory of multimedia learning. He found that words and pictures together produced better recall and transfer than either did alone, and that individual differences in ability were a factor. More recently, he (2003b)[31] further conducted a review of research on the design of multimedia explanations, which shows as follows:

- a multimedia effect-in which students learn more deeply from words and pictures than from words alone-in both book-based and computer-based environments

- a coherence effect - in which students learn more deeply when extraneous material is excluded rather than included-in both book-based and computer-based environments

- a spatial contiguity effect - in which students learn more deeply when printed words are placed near rather than far from corresponding pictures - in both book-based and computer-based environments.

- a personalization effect - in which students learn more deeply when words are presented in conversational rather than formal style-both in computer-based environments containing spoken words and those using printed words.

He found that the media consisting of printed text and illustrations were able to produce a strong multimedia effect. Moreover, he concluded that the promise of multimedia learning lay in the potential of using words and pictures in ways that promoted meaningful learning.

Followed by Mayer's study, Liu (2004)[28] investigated the role of comic strips on ESL learners' reading comprehension. According to the students' proficiency, he organized them into a low intermediate-level proficiency group (low-level students) and a high intermediate-level proficiency group (high-level students). He found that the low-level students receiving the high-level text with the comic strip scored significantly higher than their counterparts receiving the high-level text only. His findings along with Mayer's are correspondent with DCT. However, he also found that providing a comic strip with the high-level text did not enhance the high-level students' recall. Hence, he questioned Sadoski and Paivio's (2001)[29] claim that the DCT is universal.

\subsubsection{The Input Hypothesis}

The Input Hypothesis, a group of five hypotheses of second language acquisition, was proposed by Krashen in the 1970s and 1980s. The hypothesis consists of five main hypotheses: (1) the acquisition-learning hypothesis; (2) the natural order hypothesis; (3) the monitor hypothesis; (4) the input hypothesis; (5) the affective filter hypothesis. In fact, Krashen originally formulated the input hypothesis as just one of the five hypotheses; however, the term has gradually referred to the five hypotheses as a group. The researcher, here, only introduces the last two hypotheses.

According to Krashen (2004)[5], the input hypothesis includes the following key concepts:

- The hypothesis stresses acquisition instead of learning.

- Learners acquire by understanding language that contains structure a little beyond their current level of competence $(i+1)$. This is done with the assistance of context or extra-linguistic information.

- $\mathrm{i}+1$ will be provided automatically when there is enough comprehensible input.

- Production ability emerges, not being directly taught.

Krashen emphasized the importance of comprehensible input (CI). He claimed that learners can acquire languages in which they are exposed to the language structure that exceeds their current level of competence. His hypothesis was apparently contrastive to the perspective that we learn structures first and then we reach the level of fluency by practicing them in the communication. As Krashen (2004)[5] put, "we acquire by 'going for meaning' first and as a result, we acquire structure" (p. 21)!

\subsubsection{The Affective Filter Hypothesis}

The affective filter hypothesis is the fifth hypothesis of Krashen's input hypothesis. The hypothesis stated that affective factors can affect our language acquisition. Three of the main affective factors are motivation, self-confidence and anxiety. Krashen hypothesized that language acquisition is inversely proportional to the Affective Filter. In other words, the higher the Affective Filters learners meet, the lower language acquisition they acquire. As Krashen (2004) [5] narrated, "...input is the primary causative variable in second language acquisition, affective variables acting to impede or facilitate the delivery of input to the language acquisition device" (p. 32). He implied that comprehensible input and a situation with a low affective filter are the prerequisites for the success of language acquisition.

In spite of the popularity and influence of the affective filter hypothesis, Krashen's claim was questioned that affective factors alone account for individual variation in second language acquisition (Zafar, 2009). For example, children also experience different affective factors such as motivation, self-confidence, and anxiety that supposedly account for child-adult differences in second language learning; however, despite the circumstance, children successfully master L1 - how and why?

Moreover, Krashen claimed that adults are still "acquirers" so some of them can acquire a second language to a native-like competence. Zafar (2009)[32] continued questioning, "How does the filter determine which parts of language are to be screened in/out?" That is to say, the hypothesis failed to explain how affective factors alone account for individual variation in second language acquisition. 


\subsection{Context in L2 Vocabulary Acquisition}

Numerous studies have displayed that context plays an important role in L1 vocabulary acquisition (Fraser, 1999; Nagy, 1997; Sternberg, 1987).[33][34][35] From the results of the experimental study, Nagy et al. (1997) confirmed that incidental learning from context contributes to a substantial amount of the vocabulary growth that occurs during the school years. Nagy (1997) [34] reiterated that most of students' knowledge of those words must be attributed to encounters with the words in context. Diakidoy (1998) [36] explored that the influence of reading comprehension on the acquisition of word meanings from context and to compare it to the effects of local context characteristics, such as proximity and directness of context clues. She found that reading comprehension level and prior main concept knowledge facilitated vocabulary learning from context. Furthermore, she elaborated that readers who tend to engage in inferential processing may develop a mental representation of text meaning, thereby contributing to word meaning acquisition.

Compared with the plausible hypothesis in L1 inferencing from context, context has played a controversial role in L2 vocabulary acquisition. On the one hand, some researchers argue that context plays a relatively less important role and instead, explicit instruction an apparently greater role in second-language learners' vocabulary acquisition. Their perspective is based upon the reason that second-language learners won't be effective at using context until they achieve advanced level of L2 proficiency. In the following studies, some suggestion concerning explicit learning of vocabulary is likely to be responsible for most L2 vocabulary learning (Laufer, 2001).[37]

On the other hand, since Milton and Meara (1995)[38] highly praise that context plays an indispensible role in L2 vocabulary acquisition. Till nowadays, it is a growing number of researchers begin to probe into the deeper relationship between context and L2 vocabulary acquisition. Monzó and Calvo's (2002)[39] investigated that context constraints affect inference processing differently for high and low vocabulary readers. They found that enhanced constraints are more beneficial to low vocabulary readers than high vocabulary readers; besides, reduced constraints were detrimental for low but not for high vocabulary readers. The result is consistent with Elgort and Warren's (2014) [40]investigation. Elgort and Warren's (2014) found that learners' lexical proficiency is inversely proportional to the number of contextual encounters. In other words, the lower the learner's lexical proficiency, the more contextual encounters with a new L2 word were necessary for the learning to occur. Monzó and Calvo's findings further imply that teachers should carefully choose proper context on the basis of readers level of proficiency when proceeding the instructin of inferring from context.

Most recently, Elgort and Warren (2014) [40]investigated acquisition of second language vocabulary from reading a connected authentic text. They further unveiled that a complex landscape of contextual L2 word learning in which individual differences, lexical and text characteristics individually and together affect L2 lexical development from reading. For example, they found that contextual word learning is highly related to readers' conception of vocabulary. That is, if readers regard vocabulary items as new forms and attempts to infer their meanings from context, then contextual word learning is more likely to occur.

\subsubsection{Guessing Words from Context}

A growing number of studies have shown that inferencing from the context plays an important part in reading comprehension and vocabulary gain. Nagy (1997)[34] state that "...incidental learning from context accounts for a substantial proportion of the vocabulary growth that occurs during the school years" (p. 233). In fact, when encountering unknown words, a large proportion of learners often infer the meaning of words from context based upon their knowledge background. It is widely assumed that L1 learners acquire a substantive amount of vocabulary this way. Concerning L2 inferencing from context, researchers reach no consensus on its effects. Some claimed that it does facilitate learners' reading comprehension and vocabulary gain (Nagy ,1997). [34]Moreover, recently more and more researchers have investigated the deeper relationship between different strategies and knowledge sources used to infer word meanings from context and success in lexical inference ( Webb, 2008a).[42] Elgort and Warren's (2014) [40] aimed to determine whether background knowledge moderated the relationship between passage comprehension and lexical input processing outcomes, such as intake and receptive gain and retention of target-word meanings. The results suggest that the more learners are efficient in engaging in the various processing activities required during L2 reading, the greater memory for linguistic elements they experience, including orthographic forms and semantic aspects of new lexical items.

Webb (2008a) [42]investigated the effects of context on EFL university students' vocabulary acquisition. He found that the target words in the more informative contexts and the contexts containing more contextual clues are greatly conducive for the participants to gain knowledge of meaning. Furthermore, he found that to learn the meaning of a word is not necessarily because of the number of encounters but because of the quality of the context. As researchers have different viewpoints toward the effects of L2 inferencing from context, so do they show different pedagogical suggestions. Some researches consider that teachers should integrate inferring from context into the vocabulary instruction (Elgort and Warren, 2014; Webb, 2008a). [40][42]Fraser (1999) [33]holds a positive opinion about inferring from context. He stated, "... it can have an indirect effect by decreasing the number of unfamiliar words ignored and increasing the quality of inferences" (p. 239) Similarly, Elgort and Warren asserted that L2 lexical processing should be developed in instructed vocabulary acquisition because it is critical for contextual word learning. Webb (2008a) 
[42]claimed that teachers are supposed to know the importance of the effects of context on incidental learning. Moreover, "they need to consider how the context may affect learning, and judge whether target words are likely or unlikely to be learned" (p. 240). Teachers must alert their students to the problem, informing them that building a vocabulary requires a great deal of work in case that the cumulative effect of misinterpretation happens.

\section{Method}

\subsection{Subjects and Instruments}

The present study aims to investigate the effects of English comic books on EFL junior high school students' vocabulary acquisition, reading comprehension, and English learning motivation. The participants in this study were 28 eighth graders from one class in a public junior high school in Pingtung. According to the participants' mean score of three English mid-term examinations in the prior semester before the experiment, they were divided into two proficiency groups: the high-proficiency group (HG)-the top 33 percent of the population and the low-proficiency group (LG)-the bottom 33 percent of the population. The whole experiment lasted for ten weeks. In the first week, all of the participants had to take a vocabulary pretest on 50 target words selected from the three designated English comic books and a reading pretest adapted from The First Basic Competence Test of English for Junior High School Students in 2010. Besides, a pre-study questionnaire was also carried out. From the second to the ninth week, the participants finished reading an English comic book every three weeks. During the experiment, they read three comic books in total. In the last week, the participants needed to take two tests, a vocabulary post-test on 50 target words and a reading post-test adapted from The Second Basic Competence Test of English for Junior High School Students in 2010. In the end, a post-study questionnaire was administered.

\subsection{Data Analysis}

In order to investigate to what extent English comic-book reading increased the subjects' vocabulary acquisition and reading comprehension together with their motivation and attitudes towards English learning before and after the treatment, six kinds of data were collected from 1 . the vocabulary pretest; 2 . the vocabulary post-test; 3 . the reading pretest; 4 . the reading post-test; 5 the pre-study questionnaire; and 6 the post-study questionnaire. Based upon the purposes of the research, they were analyzed in the quantitative or qualitative manner.

In the quantitative analyses, the statistics were computed out through the statistical software SPSS. A Pearson Product Moment Correlation, which was used to examine the extent of correlation between two tests. Another was an independent-samples $t$-test was used to compare the differences between two independent groups. Still another was a paired-samples $t$-test, which was used to compare the before and after differences for the same group. The other was the descriptive statistics, which was used to show the numerical values such as the mean score and the standard deviation. In the qualitative analyses, the subjects' reposes to the open-ended questions in the post-study questionnaire were examined and summarized so as to find out the answers to the research questions in the study. With the qualitative analyses, the researcher may understand the possible effects of the English comic-book reading on the subjects' vocabulary acquisition and reading comprehension.

\section{Results}

Based upon the quantitative and qualitative data analysis, the findings of the present study are summarized as follows.

First of all, according to the participants' scores from the vocabulary pretest to the post-test, all of them significantly improved their amount of vocabulary after the comic-book reading program (CBRP). As for the contrast between the HG and the LG, the former outperformed the latter and the result reached a significant difference. Meanwhile, the difference also reached a statistical significance. That is, the program did improve the subjects' vocabulary acquisition. The striking improvement mainly resulted from the pleasure of reading comics, abundant contextualization and curricular practices.

Second, based on their scores from the reading pretest to the post-test, all of them enhanced their reading comprehension ability posterior to the CBRP and the result reached a significant difference. As for the respective performance between the HG and the LG, the former was better than before and reached a significant difference; the latter was better than before but failed to reach a significant difference. Concerning the contrast between the two groups' reading enhancement, the HG performed better than the LG; nonetheless, their difference failed to reach a statistical significance. the program also obviously enhanced the subjects' reading comprehension; besides, the difference reached a statistical significance. The salient enhancement was consistent with the previous related studies which had shown that visuals benefited L2 readers' reading comprehension such as Liu (2004).[28]

Third, compared with the average vocabulary gain between the high-proficiencygroup (HG) and the low-proficiency group (LG), it was clearly observed that the HG outperformed the LG. Meanwhile, the difference between the two groups' vocabulary gain also reached a statistical significance. What's more, both of the two groups respectively reached a statistical significance. Two possible explanations were as follows. On the one hand, the high-proficiency learners were more likely to perform better than the low-proficiency ones. On the other hand, contrastive to the former, the latter were oftentimes hindered from acquiring vocabulary owing to their limited 
knowledge of words.

Fourth, compared with the average scores of reading enhancement between the $\mathrm{HG}$ and the LG, the HG performed better than the LG. However, the difference between the two groups' reading enhancement reached a non-statistical significance. Moreover, the difference of the former reached a statistical significance while the latter failed to reach a statistical significance. From the results of the statistics, both of them made progress after the program. Additionally, the HG performed better than the LG; nonetheless, their difference failed to reach a statistical significance.

Fifth, in terms of the subjects' attitudes toward the CBRP, positive responses were found in the post-study questionnaire. Most of them agreed that they like to read English comic books more than before and they thought that it's a good way to apply English comic books as supplementary materials. Besides, a large majority of them agreed that reading English comics did improve their vocabulary acquisition and reading comprehension. According to the analysis of the questionnaires, up to $86 \%$ of them think it is a good way to apply English comic books to English instruction; about $79 \%$ of them agreed that they like to read English comic books better than before.

Accordingly, English comic-book reading can improve EFL junior high school students' vocabulary acquisition and enhance their reading comprehension. What's more, it also heightens their learning attitudes. Reading for pleasure and reading without looking up all the unknown words were both highly correlated with overall language proficiency.

\section{Implications and Suggestions}

\subsection{Implications}

As displayed in the major findings of the research, English comic-book reading surely facilitated the subjects' vocabulary acquisition and reading comprehension. As a consequence, based upon the findings, the following pedagogical implications were proposed.

First of all, instructors should not teach the subjects too many reading skills or make them do the excessive drills. Otherwise, the subjects often feel bored and the English comic books become another kind of textbooks. As Smetana et al. (2009) [43] stated, " ...teachers spend so much time teaching discrete skills that the pleasure of reading is reduced and reading becomes rote and dry" (p. 231). Therefore, instructors should strike the balance between "artificial instruction" and "natural reading pleasure".

Secondly, instructors need to choose proper English comic books for reading and learning. Two aspects should be taken into consideration. One is the subjects' interest and their levels of proficiency and the other is the difficulty level of materials. An appropriate English comic book can not only spark the subjects' interest but also enhance their learning effects.
Thirdly, instructors may provide the LG with additional help to further enhance its reading comprehension. From the results of the research, it is clearly found that the LG made slight progress in the reading comprehension. Their average score of reading enhancement was only 5 points and the difference failed to reach a statistical significance. For example, instructors should equip them with more background knowledge about the stories, helping them get the main idea as much as possible. Besides that, instructors should offer them more hints concerning the new words, assisting them to overcome the barrier of the vocabulary.

Fourth, reading English comic books also facilitates their ability of visual literacy. Comics should be offered to children as reading materials because visual literacy is increasingly a greater part of our lives in the 21 st century. Therefore, instructors shouldn't worry that pictures may hinder students' reading comprehension; instead, pictorial representation may promote their abilities of visual literacy.

In sum, integrating comics into language instruction will become more and more popular in the future because it plays an important role in cultivating the learners' abilities of visual literacy. Moreover, to enhance its effects, instructors need to balance the instruction time, select proper English comic books and offer additional help to the low-proficiency learners.

\subsection{Suggestions}

The present study examined the relationship between English comic-book reading and vocabulary acquisition together with reading comprehension for EFL junior high school students. It is hoped that the findings of this study can offer some pedagogical suggestions to instructors interested in this field and encourage future researchers to better similar studies. Because of the limitations in the present study, the following suggestions for future studies are provided.

First, a larger group of subjects are suggested for the future studies. Because of convenience in carrying out the research, only 28 subjects participated in it; however, the limited number of them can't be generalized to all the other EFL junior high school students in Taiwan. As a consequence, the researcher suggests that there should be more subjects in the future research. By so doing, there will be bigger statistical power and the results will be even more convincing.

Second, the length of the treatment for the future studies can be prolonged. The nine-week experiment was conducted due to the time constraint. There were only short-term effects of English comic books on the subjects' vocabulary acquisition and reading comprehension. Because both vocabulary acquisition and reading comprehension are cultivated in the progressive and incremental process, future researchers can prolong the study time to compare their findings with those of the present study.

Third, more and different kinds of English comic books can be read in the future studies. During the present study, 
only three English comic books were read. The effects of reading comprehension may be limited by the small number of the books. Consequently, the number of English comic books is suggested to be added in the future studies to examine the effects of reading comprehension. In addition, the English comic books adopted in the study were from the textbooks because they were easily accessible. However, the same type of comics may not be generalized to all genres of comic books. Thus, different kinds of comics should be used to examine the effects in the future research.

Last but not least, learners' L2 retention can be tested in the future studies. Although the present study presented English comic-book reading's effects on learners' vocabulary acquisition and reading comprehension, the effect of the retention wasn't tested in this study. Therefore, the effect of learners' retention can be tested in the future research.

To sum up, although this study has shown that reading English comic books can improve the learners' vocabulary acquisition and reading comprehension, there are some suggestions for instructors and future researchers who are interested in this topic. They can enhance the effects of English comic book reading in the ways of inviting a larger number of subjects, reading more and different kinds of English comic books, prolonging the time and carrying out the test of retention.

\section{REFERENCES}

[1] C. H. Prator, M. Celece-Murcia. An outline of language teaching approaches. In M. Celce-Murcia, \& L. McIntosh (Eds), Teaching English as a second or foreign language. New York, NY: Newbury House, 1979.

[2] W. Grabe. Reading in a second language: Moving from theory to practice. New York: Cambridge University Press, 2009.

[3] C. A. Perfetti, N. Landi, J. Oakhill. The acquisition of reading comprehension skills. In M. J. Snowling \& C. Hulme (Eds.), The science of reading: A handbook (pp. 227 - 247). London, England: Blackwell, 2005.

[4] D. Zhang. Vocabulary and grammar knowledge in second language reading comprehension: A structural equation modeling study, The Modern Language Journal, Vol. 96, 4-15, doi: $10.1111 / \mathrm{j} .1540 \quad$ - 4781.2012.01398.x 0026-7902/12/558 - 575, 2012.

[5] S. D. Krashen. The power of reading: insights from the research (2nd ed.). Westport, Conn.: Portsmouth, NH: Heinemann: Libraries Unlimited, 2004.

[6] N. Frey, D. Fisher. Vocabulary Learning Across Content Areas. Principal Leadership, Vol. 14, No. 8, 56-59, 2014.

[7] D. Jacobs. More Than Words: Comics as a Means of Teaching Multiple Literacies. English Journal, Vol. 96, No.3, 19-25, 2007.

[8] R. Nixon. Teaching Narrative Writing Using Comics:
Delainey and Rasmussen, the Creators of "Betty," Share Their Composing Strategies as Rich Literacy Resources for Elementary Teachers. Literacy, Vol. 46, No. 2, 81-93, 2012.

[9] L. C. Serantes. Slighting Certain Kinds of Readers: Searching for Comic Book and Graphic Readers in Library and Information Science Literature, 2010.

[10] M. Bongco Reading comics: Language, culture, and the concept of the superhero in comic books. Routledge, 2014.

[11] T. Pughe (2013). Comic Sense: Reading Robert Coover, Stanley Elkin, Philip Roth. Birkhäuser.

[12] M. P. Brown. The Thick Style: Steady Sellers, Textual Aesthetics, and Early Modern Devotional Reading. PMLA, 67-86, 2006.

[13] S. S. Choo. Writing through visual acts of reading: Incorporating visual aesthetics in integrated writing and reading tasks. The High School Journal, Vol. 93, 166-176, 2010 .

[14] H. Chute. Comics as literature? Reading graphic narrative. PMLA, 452-465, 2008.

[15] J. M. Davis. Pictorial Irony, Parody, and Pastiche: Comic Interpictoriality in the Arts of the 19th and 20th

[16] P. Flaig. Life driven by death: animation aesthetics and the comic uncanny. Screen, Vol. 54, No.1, 1-19, 2013.Centuries. The British Journal of Aesthetics, ays050, 2012.

[17] R. A. Gardner. Jaqueline Berndt was granted her Ph. D. in aesthetics at Humboldt University Berlin in 1991, and is currently an associate professor (joky $\div$ oju) for Art and Media Studies, Yokohama National University. Her research interests are in the aesthetics of comics, modern art in Japan, and contemporary visual culture. Her manga-re-lated publications include: Phänomen Manga. Comic-Kultur in Japan (edition q. Japanese Visual Culture: Explorations in the World of Manga and Anime, 335, 2014.

[18] A. D. Lewis. The shape of comic book reading. Studies in Comics, Vol. 1, No.1, 71-81, 2010.

[19] P. Stockwell. Texture: A cognitive aesthetics of reading. Edinburgh University Press, 2012.

[20] T. G. Morrison, G. Bryan, G. W. Chilcoat. Using student-generated comic books in the classroom. Journal of Adolescent \& Adult Literacy, Vol. 45, No. 8,758-767, 2002.

[21] D. Viadero. Scholars See Comics as No Laughing Matter. Education Week, Vol. 28, No. 21, 1-11, 2009.

[22] J. B. Carter. Building Literacy Connections with Graphic Novels: Page by Page, Panel by Panel, 2007.

[23] S. Cleaver. Comics \& Graphic Novels. Instructor, Vol. 117, No. 6, 28-34, 2008.

[24] B. Norton, K. Vanderheyden. Comic book culture and second language learners. In B. Norton \& K. Toohey (Eds.), Critical pedagogies and language learning (pp. 201-222). New York, NY: Cambridge University Press, 2004.

[25] J. Ranker. Using Comic Books as Read-Alouds: Insights on Reading Instruction From an English as a Second Language Classroom. The Reading Teacher, Vol. 61, No. 4, 296-305. doi:10.1598, 2007. 
[26] C. Bringelson Comics in the Educational Sphere. School Library Monthly, Vol. 26, No.10, 23-23, 2010.

[27] C. W. Chun. Critical Literacies and Graphic Novels for English-Language Learners: Teaching "Maus." Journal of Adolescent \& Adult Literacy, Vol. 53, No. 2, 144-153. doi:10.1598/JAAL.53.2.5, 2009.

[28] J. Liu. Effects of Comic Strips on L2 Learners' Reading Comprehension. TESOL Quarterly, Vol. 38, No.2, 225-243. doi:10.2307/3588379, 2004.

[29] M. Sadoski, A. Paivio. Imagery and text: A dual coding theory of reading and writing. Mahwah, NJ: Lawrence Erlbaum, 2001

[30] R. E. Mayer. Learning and instruction. Merrill Upper Saddle River. New Jersey: Pearson Education, Inc, 2003a.

[31] R. E. Mayer. The promise of multimedia learning: using the same instructional design methods across different media. Learning and Instruction, Vol. 13, 125-139, 2003b.R. F. Voss, J. Clarke. Algorithmic Musical Composition, Silver Burdett Press, Londyn, 1986.

[32] M. Zafar. Monitoring the 'monitor': A critique of Krashen's five hypotheses. Dhaka University Journal of Linguistics, Vol. 2, No. 4, 139-146, 2009.

[33] C. A. Fraser. Lexical processing strategy use and vocabulary learning through reading. Studies in Second Language Acquisition, Vol. 21, No. 225-241, 1999.

[34] W. Nagy. On the role of context in first- and second-language vocabulary learning. In N. Schmitt \& M. McCarthy (Eds.), Vocabulary: Description, acquisition and pedagogy (pp. 64-83). Cambridge: Cambridge University Press, 1997.

[35] R. J. Sternberg. Most vocabulary is learned from context. In
M. G. McKeown, M. E. Curtis (eds) The nature of vocabulary acquisition. New Jersey, London: Lawrence Earlbaum Associates, Publishers, 89-105, 1987.

[36] I. Diakidoy. The role of reading comprehension in word meaning acquisition during reading. European Journal of Psychology of Education, Vol. 13, 131-154, 1998.

[37] B. Laufer. Reading, word-focused activities and incidental vocabulary acquisition in a second language. Prospect, Vol. $16,44-54,2001$.

[38] J. Milton, P. M. Meara. How periods abroad affect vocabulary growth in a foreign language. International Review of Applied Linguistics, Vol. 107, No.108, 17-34, 1995.

[39] A. E. Monzó, M. G. Calvo. Context constraints, prior vocabulary knowledge and on-line inferences in reading. Psicothema, Vol. 14, 357-362, 2002.

[40] I. Elgort, P. Warren. L2 Vocabulary Learning From Reading: Explicit and Tacit Lexical Knowledge and the Role of Learner and Item Variable. Language Learning, Vol. 64, No.2, 365-414. doi:10.1111/lang.12052, 2014.

[41] D. P. Hayes, M. Ahrens. Vocabulary simplification for children: A special case of "motherese."Journal of child language, Vol. 15, NO.2, 395-410, 1988.

[42] S. Webb. Receptive and productive vocabulary sizes of L2 learners. Studies in Second Language Acquisition, Vol. 30, 79-95, 2008.

[43] L. Smetana, D. Odelson, H. Burns, D. L. Grisham. Using graphic novels in the high school classroom: Engaging deaf students with a new genre. Journal of adolescent \& adult literacy, Vol. 53, No. 3, 228-240, 2009. 